\title{
Research Progress on the Development of Strategy Consumers' Behavior
}

\author{
Yizi Jiang \\ Institute of Rail Transit, Tongji University, Shanghai 201804, China \\ 595266080@qq.com
}

Keywords: strategic customer behavior, inventory, capacity rationing, retailer.

\begin{abstract}
In the face of favorite goods, consumers may not buy immediately, but be patient to wait for discounts. We call such a consumer as a strategic consumer. Different from myopia consumers, Strategic consumers will try to predict the price and promotion strategies of sellers to determine the appropriate purchase behavior. For businesses, the neglect of strategic consumers' behaviors will bring huge economic losses. Therefore, it is important to study the impact of consumer behaviors on vendors and how to mitigate the impact of strategic consumers' behaviors. This paper introduces the definition of strategic consumers' behaviors and the specific behavior patterns, and analyzes the influencing factors of strategic consumers' behaviors. Finally, it summarizes the research process of the mitigation strategy of strategic consumers.
\end{abstract}

\section{Introduction}

In our daily life, there is a large number of such a group of consumers that may not buy favorite commodities immediately, but wait patiently when the discount is enough to buy. Strategy consumers are different from myopia consumers, and they will predict the business of pricing and promotion strategies to determine the appropriate time to purchase. It is worthy of business and scholars considering about the common phenomenon of strategy consumer groups.

Strategic consumer behavior has long been a research interest among scholars. Since Coase [1] proposed the price difference firstly, it means that solding at high prices for consumers who have the high valuation and low prices for consumers who have the low valuation. The management of strategy consumer behavior has aroused extensive research interest in academic circles. Especially in recent years, the emergence of a large number of research literature. Aviv and Levin [2] made a comprehensive review.

The emergence of strategic consumer groups poses a major challenge for retailers and manufacturers alike. Retailers always want to sell the goods at the best price, while consumers are always waiting for a price reduction, and the two want their profit to be maximized. This game will continue indefinitely. Faced with more and more economic rationality to maximize the strategy of consumers, how to deal with how the game has become one of the most difficult problem.

This paper examines the specific factors that influence strategy, consumer behavior patterns, and strategic consumer behavior. Finally, the author has proposed various coping strategies that vendors have taken,furthermore, is hoping to get more practical and effective ways to alleviate the influence of consumer behavior.

\section{Strategic Consumer Behavior}

Strategic consumers are different from myopic consumers. Cachon and Swinney [4] divides consumers into three categories, and depicts the valuations of different types of consumers. Myopic consumers, also known as the impulsive consumers, will buy favorite products immediately, if the product is lower than the price of their valuation, not deliberately wait to buy in discount period. The strategic consumers, also known as the strategic patrons, may not buy favorite products 
immediately, even if the product is lower than the price of their valuation, but are waiting for the discount period to purchase for maximizing their expected return. Bargain hunting coustomers will never buy in the initial stage, and always wait for the discount period to buy the product.

\section{The Behavior Patterns of Strategic Consumer}

Analysis of consumer behavior model is the basis of this paper, according to the relevant research, it can have more comprehensive analysis of manufacturers or enterprises pricing strategy. The strategic consumer behavior is mainly focused on the impact of firm's dynamic pricing on consumer behavior, which can be divided into two-period and multi-period models that depending on the number of price changes.

(1) The strategy consumer behavior model under single product and two cycle price

Liu et al. [11] studied the selection process of the strategy consumers in the face of the two-cycle pricing firms. Assuming that the prices of the two periods are $p 1$ and $p 2(p 1>p 2)$, the consumer's evaluation of the product is $v$, when $v>p 1$, the utility of the consumer in the first stage of the purchase of the product is $u(v-p 1)$, if in the second stage, the obtained utility of purchase is the $u$ $(v-p 2)$, because of lower prices, the possibility of consumers buying the product is $\varphi$, the possibility of not buying the product is $1-\varphi$, whose obtained utility is 0 , the strategy-making process is shown in figure 1 . When the consumer's evaluation of the product satisfies $u(v-p 1)>$ $\varphi u(v-p 2)$, the customers will purchase the products in the first stage.

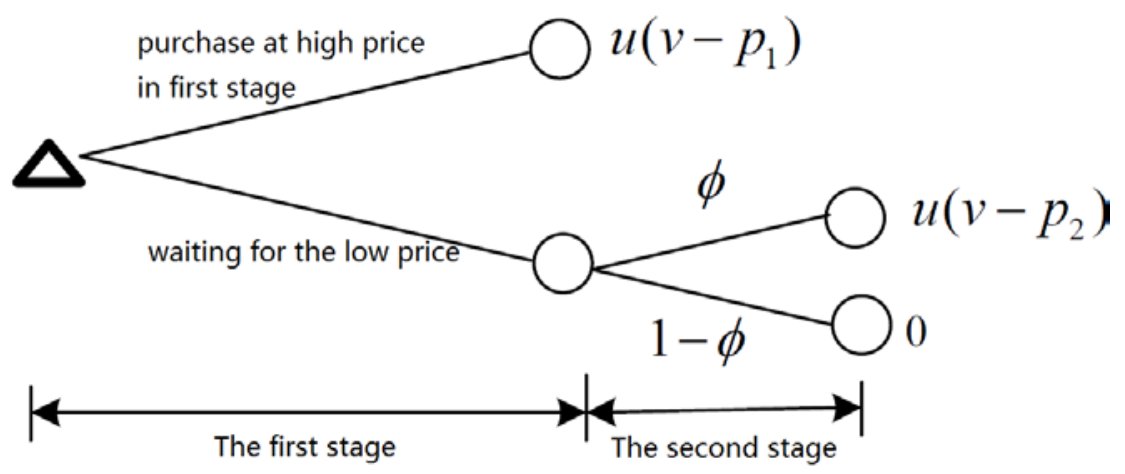

Fig. 1 The diagram of two-cycle strategy consumer strategy-making

Strategy 1: low-cost listing -- low selling strategy; strategy 2: high-priced listing -- low selling strategy; strategy 3: high-priced listing -- high selling strategy [5].

(2) The strategy consumer behavior model under single product and multi-cycle price

Besanko and Winston [6] worked on the research of the rational consumer pursuing the pursuit of long-term utility to maximize the problem based on the vendor's dynamic pricing, assuming that consumer evaluation of the product decreases with time, consumers fully understand the future price will change, they will choose the utility to maximize the time to buy. Liu and Zhang [7] extended the above model, the introduction of different quality alternative to the two products, consumers not only want to choose a product of the best time to buy, but also make a choice between the two products.

The above two documents are implied by the manufacturer's production capacity being not limited. And the manufacturers only need to consider the development of dynamic prices, there is no need to determine the output. Zhou et al. [8] introduces the behavior of the strategy consumer when the price changes are many times based on the Gallego and van Ryzin [9] models, assuming that the consumer is bounded rationality and will compare the influence of purchasing the product at two adjacent sales periods before making the decision.

Assuming that the consumer evaluation of the product is $v$, the price of the product is $p(n, t)$ when the remaining product quantity is $n$ and the remaining sales time is $t$.

The utility of the immediate purchase of the consumer is $v-p(n, t)$, if the remaining time is $t$ $\Delta t$ when the purchase, then the probability of the remaining goods is $1-\lambda \Delta t+o(\Delta t)$, the 
probability of the remaining $n-1$ goods is $\lambda \Delta t+o(\Delta t)$, the probability of the other cases is $o(\Delta t)$, then the expected utility of the purchase when the remaining time is:

$(1-\lambda \Delta t) \max \{0, v-p(n, t-\Delta t)\}+\lambda \Delta t \max \{0, v-p(n-1, t-\Delta t)\}+o(\Delta t)$,

When meeting $v-p(n, t)>(1-\lambda \Delta t) \max \{0, v-p(n, t-\Delta t)\}+\lambda \Delta t \max \{0, v-p(n-1, t-\Delta t)\}$

$+o(\Delta t)$, the consumers will buy it immediately, otherwise will wait.

\section{Influencing Factors of Strategic Consumer Behavior}

Each industry has its own characteristics, not all of which have strategic consumer behavior. The extent of the influence of strategic consumer behavior is also different for sellers. The main factors affecting consumer behavior are the following:

First, the waiting cost of consumers. Consumer demand for different products is often different. On non essentials, waiting cost of consumers is relatively low. At this time, consumers often game boldly with the business and are more inclined to choose the discount period when purchasing products. The impact of strategic consumer consumer behavior on the retailer is more serious. However, for the necessities of life and emergency supplies, waiting cost of consumer is relatively high. At this time, consumers tend to buy products at the first sales period, rather than waiting for discount period. The conclusion is that consumers are everywhere in the clothing and other fashion field. Meanwhile the strategic consumer behavior is not prominent in the daily activities field and the impact on the retailer is relatively small.

Second, retailers' pricing strategy. The reason why consumers defer buying behavior is that they expect the retailers' dynamic pricing according to the retailers' previous pricing strategy. There will be no strategic consumer behavior if retailers do not resort to promotions such as seasonal discounts, anti-season promotions in the field, or have not a room for price reductions.

Third, inventory quantity of retailers. The number of inventory will also affect the strategic consumer behavior. If the product inventory of the retailer is limited, the strategic consumer will expect: if the product is discounted, it is likely to be out of stock due to insufficient supply. As a result, consumers tend to buy at the beginning of the sale. But if the retailer's product inventory often remaining, consumers will expect that is possible to obtain a discount productthis and choose to wait for discount period.

As a result, there are many factors influencing consumer strategies. The characteristics of the product determine the waiting cost of the consumer. The inventory and pricing strategies also influence the decision of the strategic consumers behavior, thus further affecting the profits of the retailers.

\section{Research Progress on Reducing of Strategic Consumers Behavior Effect}

Many scholars mainly study how to deal with strategic consumers behaviors by the following aspects.

\subsection{Differentiated pricing strategy}

Coase based on the monopoly market to study the pricing strategy of the seller [1]. Research shows that: ideally, vendors want to be able to achieve price differentiation, and it means that solding at high prices for consumers who have the high valuation and low prices for consumers who have the low valuation. But if highly valued consumers expect product prices to fall, consumers tend to postpone buying behavior, resulting in strategic consumers' behaviors that ultimately leads vendors to sell their products at marginal cost. Coase has proposed a series of ways to avoid this consequence, such as establishing a contract with the purchaser to ensure that the product is limited, and the seller gives some compensation to the consumers who bought the product at an early price. Besanko and Winston [6] introduced a game theory model to study strategic consumers' behaviors how to deal with the heterogeneous valuation under the monopoly market. The results show that the initial price of the consumer when the consumer is near vision is higher than the initial price when the consumer is the strategic consumer. 


\subsection{Price commitment strategy}

Aviv and Pazgal [3] Assuming that the seller announces the price of the two periods in advance, and the price of the second period will not change with the remaining inventory. On the surface, the fixed price of the two periods is not the best strategy for the seller, since it seems that if the second period of the price increases with the inventory of the seller can get more benefits. However, when the strategic consumers' behavior exists, it is not the fact. Su and Zhang also conducted a study of price commitments aimed at raising the overall revenue of the supply chain under the strategic consumers' behavior through price commitments and proposing corresponding repurchase contracts in a decentralized supply chain model to ensure the fulfillment of price commitments.

\subsection{Limit inventory strategy}

The seller through the quota ration led to deliberately out of stock, thereby increasing the risk of out of stock, causing consumers to buy in advance. Liu and van Ryzin [11] studied the impact of quota rationing on consumer buying behavior, assuming that sellers proclaimed two-periods prices and inventory levels ahead of time, and consumers need to weigh the immediate utility of purchasing and postpone the purchase risk. The results show that the quota allocation strategy can induce consumers to buy ahead of time. Cachon and Swinney [4] studied the two-periods dynamic inventory and pricing strategy, assuming that the initial price is fixed and the price of the second period changes with the inventory. The seller needs to make the optimal inventory and secondperiod price for maximizing profits.

\subsection{Internal price matching strategy}

The internal price matching strategy is a strategy to guarantee the price and is in the future period of time, if the product price, the seller will make sure that compensation for price difference to the consumer. The Compensation for price difference are common in retail, and there are corresponding sites (refundapleas.com) to help consumers monitor product price changes at all times.

\subsection{Limit information of inventory strategy}

In the study of limited inventory information, Yin et al. [15] proposed a game theory model of the sale of limited inventory products by the seller during the limited period of sale, in which two methods of public inventory information were used: Open all the inventory information and open part of the inventory information. In the case of opening all inventory information, the consumer knows all remaining inventory. In the case of opening part of the inventory information, consumers only know whether there is any remaining inventory, but do not know the inventory level. The results show that opening part of the inventory information can increase the consumer's perception of out of stock, induced consumers to buy in advance.

\subsection{Quick response and improving product quality strategy}

In terms of quick response and improving product quality, Cachon and Swinney [4] first proposed a quick response strategy to mitigate the impact of strategic consumers' behaviors. They conducted a more in-depth study that the establishment of a traditional model, quick response model, quality model and fast fashion model to study what role of the quick response and improving product quality in consumers' behaviors. The results show that quick response and improving product quality can mitigate the negative impact of strategic consumers' behaviors on the seller's profit. And while the model of quick response and the model of improving product quality are complementary. The strategic consumer is more patient, and the quick response and improving product quality strategy is better.

\section{Conclusion}

Through the above summary and comparative analysis: the research of coping consumers' behavior has been attracted more and more international scholars' attention. Current coping strategies of the consumer behavior mainly focus on the strategies such as differentiated pricing 
strategies, price commitments, limited inventory, limited supply, internal price matching, limited inventory information, improved product quality and rapid response. But most of the above studies assume that consumers are risky and that the value assessment of products by consumers does not change over time. On the contrary, the actual phenomenon is strategic consumers tend to have different risk preferences and the value assessment of products by consumers decreases with time being decrement. The future direction of research is that taking consumers as a dynamic variable, so that the strategy will be closer to the reality.

\section{References}

[1] RH Coase. Durability and monopoly [J]. Journal of Law \& Economics, 1972, 15 (1): 143-149.

[2] Y Aviv, Y Levin, M Nediak. Counteracting strategic consumer behavior in dynamic pricing systems [J]. International, 2009, 131: 323-352.

[3] Y Aviv, A Pazgal. Optimal pricing of seasonal products in the presence of forward-looking consumers [J]. INFORMS, 2008, 10 (3): 339-359.

[4] G Cachon, P Rard, R Swinney. Purchasing, pricing, and quick response in the presence of strategic consumers [J]. Management Science, 2009, 55 (3): 497-511.

[5] ZF Mao, FY Wang.Study on two-period pricing decision of perishable goods based on consumer behavior and valuation discount [J]. Chinese Journal of Management, 2017, (03): 441450.

[6] Besanko D,WinstonWL. Optimal price skimming by a monopolist facing rational consumers [J].Management Science, 1990, 36(5): 555-567.

[7] Liu Q, Zhang D. Dynamic pricing competition with strategic customers under vertical productiondifferentiation [R]. Hong kong: Working paper, Hong Kong University of Science and Technology, 2010.

[8] Zhou Y P, Fan M, Cho M. Strategic consumer response to dynamic pricing of perishable products $[\mathrm{M}] / /$. Tang C S, Netessine S. Consumer-Driven Demand and Operations Management Models with Consumer-driven Demand. New York: Springer US, 2009: 441-457.

[9] Gallego G, van Ryzin G. Optimal dynamic pricing of inventories with stochastic demand over finite horizons [J]. Management Science, 1994, 40(8): 999-1020.

[10] W Chen, XH Xu, HX Peng. Finite and price commitment based on strategy consumer behavior [J]. Journal of Systems Engineering, 2013, (03): 307-315.

[11] Liu Q, van Ryzin G J. Strategic capacity rationing to induce early purchases [J]. Management Science, 2008, 54(6): 1115-1131.

[12] Chen Y, Zhang Z J. Dynamic targeted pricing with strategic consumers [J]. International Journal of Industrial Organization, 2009, 57(2): 327-341.

[13] Levin Y, McGill J, Nediak M. Dynamic pricing in the presence of strategic consumers and oligopolistic competition [J]. Management Science, 2009, 55(1): 32-46.

[14] Levin Y, McGill J, Nediak M. Optimal dynamic pricing of perishable items by a monopolist facing strategic consumers [J]. Production and Operations Management, 2010, 19(1): 40-60.4

[15] R Yin, Y Aviv, A Pazgal, CS Tang. Optimal markdown pricing: implications of inventory display formats in the presence of strategic customers [J]. Management Science, 2009, 55 (8): 13911408. 